\title{
Exploring the bi-directional relationship between pancreatic cancer and diabetes mellitus: a retrospective study
}

\author{
Kellam Harry ${ }^{1} \cdot$ Yim Kein-Leong ${ }^{2}$ (D) \\ Received: 25 July 2018 / Accepted: 1 November 2018 / Published online: 15 November 2018 \\ (C) Springer Nature Switzerland AG 2018
}

\begin{abstract}
Objective To explore the bi-directional between pancreatic cancer (PC) and diabetes mellitus (DM); focusing on the prevalence, temporal association and impact on survival outcomes.

Methods A retrospective audit of pancreatic cancer patients from the institutional clinical database (CaNISC) between January 2012 and April 2018.

Results A total of 131 patients were analysed, 58 patients carried a diagnosis of diabetes mellitus. The median overall survival for diabetes mellitus patients was 12.0 months (95 CI, 5.9 to 18.1 months) in comparison to 13.0 months (95\% CI, 8.6 to 17.3 months) in non-diabetes mellitus patients $(p=0.334)$.

Conclusion There was no significant difference in the overall survival between DM and non-DM patients.
\end{abstract}

Keywords Diabetes $\cdot$ Pancreas $\cdot$ Cancer $\cdot$ Association $\cdot$ Treatment $\cdot$ Outcome

\section{Aims/Objectives}

The aim of the study is to explore the bi-directional relationship between pancreatic cancer (PC) and diabetes mellitus (DM) by retrospectively equating their prevalence and temporal association. The study will also evaluate the impact of DM status on survival outcomes and to identify potential aspects that require further investigation to aid the development of clinical guidelines.

\section{Introduction}

PC is the fourth most common cause of cancer-related mortality in Wales, accounting for approximately 450 deaths per year [1]. More significantly, the incidence rate of PC is closely matched by its mortality rate. The prognostic outcomes for PC patients remains to be poor with a current five-year survival rate of just $7.4 \%$ [2]. The pathophysiological nature of PC

Yim Kein-Leong

yimk12000@hotmail.com

1 University of Cardiff, Cardiff CF10 3AT, UK

2 Velindre Cancer Centre, Cardiff CF14 2TL, UK most commonly favours a late-stage clinical presentation [3] and the current treatment options available continue to be ineffective [4]. In an attempt to improve the clinical outcomes of PC, there has been calls for more extensive research into its respective aetiology and pathology.

DM is a global burden in regard to the morbidity and mortality it carries. There is much debate around whether DM is involved in a bi-directional causal link with pancreatic cancer. The interaction is multifaceted, lacking in real clarity. This study aims to explore this intricate relationship through comparing patient characteristics and determining the impact of DM on overall survival (OS) in a sample of PC patients.

\section{Methods}

This study is a retrospective analysis of 131 consecutive patients who were diagnosed with PC at Velindre Cancer Centre between 2012 and 2018. The institutional patient database CaNISC is the local source data containing clinical patient information registered with the hospital for use in daily practice. Using the CaNISC patient database, information was obtained regarding DM and PC status, including age, gender, diagnosis dates, random blood glucose (RBG), primary tumour site, staging, anti-diabetic use and cancer treatments received. 
Pathological confirmation of $\mathrm{PC}$ was obtained through previous surgical resection specimen from pylorus-preservingpancreatico-duodenectomy (PPPD), biopsy of the primary tumour via endoscopic ultrasound (EUS), radiologically-guided biopsy of metastatic lesions, endoscopic brushings, or aspiration from malignant ascites for cytology.

Due to the rapid nature of the cancer diagnosis and initiation of oncological treatment. As life expectancy is short due to poor overall prognosis in patients with pancreatic cancer, the authors focused on factors influencing the immediate impact on patient treatment and RBG was chosen as a rapidly accessible test.

A number of different outcomes and exposure variables were investigated in this study, all of which need some degree of defining. Existing studies in this area of research have used differing criteria for defining DM [4]. In this particular study, patients were defined as having DM using the following indicators:

1. The documentation of a pre-existing or new DM diagnosis.

2. The documentation of prescribed anti-diabetic medications.

3. Evidence of glucose intolerance in the patient's blood results i.e. the documentation of 2 or more consecutive random $\mathrm{RBG}$ readings $\geq 11.1 \mathrm{mmol} / \mathrm{L}$.

The sample of DM patients were further classified into three sub-groups related to the onset of DM: pre-PC diagnosis (prePCd), at time of PC diagnosis (at-PCd) and post-PC diagnosis (post-PCd). The onset date for DM diagnosis was taken as of that recorded in the patient's CaNISC notes or the date of the second consecutive high $\mathrm{RBG}$ reading. The outcome of overall survival was considered as the duration between the date of pancreatic cancer diagnosis until the date of death or last follow up (censor date).

All statistical analyses were carried out using Microsoft Office Excel 2015 and SPSS version 20. The comparison between categorical patient characteristics was carried out using the Pearson Chi-square test, whilst the ANOVA and T tests were used for continuous patient characteristics. The overall survival for different patient groups was plotted on a Kaplan Meier curve and compared using the Log-rank test. Multi-variable analysis of overall survival was conducted using a Cox proportional hazards model. A $p$ value $<0.05$ was considered as a significant result.

\section{Results}

A total of 131 pancreatic cancer patients were analysed in this study. Following the definition criteria stated in the method, DM was identified in 58 patients $(44.3 \%)$. The mean age of DM patients was 68.5 years, $62.1 \%$ of cases were male, $65.5 \%$ of cases presented with pancreatic head tumours and
$44.8 \%$ of cases presented at Stage IV disease. $19 \%$ of DM patients had received surgery, $72.4 \%$ received chemotherapy and $24.1 \%$ received radiotherapy. The DM patients $(n=58)$ were further classified into their onset groups: pre-PCd (56.9\%), at-PCd (17.2\%) and post-PCd (25.9\%). The only statistically significant variation identified between the patient characteristics of these DM onset sub-groups, was that of those patients diagnosed with Stage $4 \mathrm{PC}-45.5 \%$ in prePCd, $80.0 \%$ in at PCd and $20 \%$ in post-PCd $(p=0.013)$. When drawing comparisons between DM and non-DM patients, the total number of patients who underwent surgery was significantly higher in non-DM patients compared to DM patients $(p=0.035)$. Also, a larger proportion of nonDM patients had an unknown site of primary tumour ( $p=$ 0.018). All clinical characteristics investigated in regard to DM status and onset subtypes are summarised along with their respective $p$ values in Tables 1 and 2 .

The cause of death in the cohort was cancer related progression. The median OS of the entire study group was 12.0 months (95\% CI, 8.5 to 15.5 months). The median OS of DM patients was 12.0 months (95\% CI, 5.9 to 18.1 months) compared to that of 13.0 months (95\% CI, 8.6 to 17.4 months) in non-DM patients (Fig. 1). The log-rank test $p$ value calculated was 0.334 , clarifying that the difference in median OS of DM patients and non-DM patients was not statistically significant. The mean survival of all variables are summarised in Table 3 along with their respective $95 \%$ confidence intervals and $\log$ rank $p$ values.

In univariate analysis (Table 4$)$, head $(p=0.004)$, body $(p=0.001)$, stage $3(\mathrm{p}=<0.0001)$, stage $4(\mathrm{p}=<0.0001)$, surgery $(p=0.038)$ and chemotherapy $(\mathrm{p}=<0.0001)$ were found to have an impact on OS. However, in multivariate analysis (Table 4), only head, body and chemotherapy were associated with OS. More specifically, patients with pancreatic head and body tumours held a higher risk of death and patients who had undergone chemotherapy held a lower risk of death.

\section{Discussion}

In both univariate and multivariate analysis, there was no comparable effect of DM status on the OS of PC patients. The multivariate cox proportional hazard model in fact highlighted a more significant role in the prognostic value of particular primary tumour sites, cancer staging and treatments. However, there was no distinct distribution between these characteristics in relation to DM status. Other literature investigating the impact of DM on OS, have displayed conflicting results, offering a variety of possible explanations around the particular trends identified. It is important to note that in most other studies, the sample sizes investigated were much larger than this study and their respective methodologies accounted for a more extensive set of co-variables. 
Table 1 Clinical characteristics by DM status in pancreatic cancer patients

\begin{tabular}{|c|c|c|c|c|c|c|}
\hline \multirow[t]{2}{*}{ Variables } & & \multirow[b]{2}{*}{ Total $(n=131)$} & \multicolumn{2}{|c|}{ DM vs Non-DM } & \multirow[b]{2}{*}{$p$ value } & \multirow[b]{2}{*}{$t$-value } \\
\hline & & & $\mathrm{DM}(n=58)$ & Non-DM $(n=73)$ & & \\
\hline \multirow[t]{2}{*}{ Sex } & Male & $76(58.0)$ & $36(62.1)$ & $40(54.8)$ & \multirow[t]{2}{*}{0.402} & \\
\hline & Female & $55(42.0)$ & $22(37.9)$ & $33(45.2)$ & & \\
\hline \multirow[t]{4}{*}{ Site of Primary Tumour } & Head & $78(59.5)$ & $38(65.5)$ & $40(54.8)$ & 0.214 & \\
\hline & Body & $24(18.3)$ & $12(20.7)$ & $12(16.4)$ & 0.532 & \\
\hline & Tail & $12(9.2)$ & $5(8.6)$ & $7(9.6)$ & 0.750 & \\
\hline & Unknown & $17(13.0)$ & $3(5.2)$ & $14(19.2)$ & 0.018 & \\
\hline \multirow[t]{5}{*}{ Stage at PC Diagnosis } & Stage 1 & $5(3.8)$ & $3(5.2)$ & $2(2.7)$ & 0.470 & \\
\hline & Stage 2 & $29(22.1)$ & $15(25.9)$ & $14(19.2)$ & 0.360 & \\
\hline & Stage 3 & $32(24.4)$ & $13(22.4)$ & $19(26.0)$ & 0.633 & \\
\hline & Stage 4 & $60(45.8)$ & $26(44.8)$ & $34(46.6)$ & 0.842 & \\
\hline & Unknown & $5(3.8)$ & $1(1.7)$ & $4(5.5)$ & 0.265 & \\
\hline \multirow[t]{2}{*}{ Surgery } & Yes & $37(28.2)$ & $11(19.0)$ & $26(35.6)$ & \multirow[t]{2}{*}{0.035} & \\
\hline & No & $94(71.8)$ & $47(81.0)$ & $47(64.4)$ & & \\
\hline \multirow[t]{2}{*}{ Chemotherapy } & Yes & $94(71.8)$ & $42(72.4)$ & $52(71.2)$ & \multirow[t]{2}{*}{0.881} & \\
\hline & No & $37(28.2)$ & $16(27.6)$ & $21(28.8)$ & & \\
\hline \multirow[t]{2}{*}{ Radiotherapy } & Yes & $30(22.9)$ & $14(24.1)$ & $16(21.9)$ & \multirow[t]{2}{*}{0.764} & \\
\hline & No & $101(77.1)$ & $44(75.9)$ & $57(78.1)$ & & \\
\hline Mean Age (years) & & 68.2 & 68.5 & 68.0 & 0.379 & 0.308 \\
\hline
\end{tabular}

Firstly, a number of studies have found no association between DM status and OS [5, 6]. In fact, one study proposed that higher BMI was associated with reduced OS in PC patients [7]. Such findings emphasise the need to distinguish the significance of aetiological factors that are shared by both PC and DM. There is also a need to investigate the impact of

Table 2 Clinical characteristics by DM onset in pancreatic cancer patients

\begin{tabular}{|c|c|c|c|c|c|c|c|}
\hline \multirow[t]{2}{*}{ Variables } & & \multirow[b]{2}{*}{ Total $(n=58)$} & \multicolumn{3}{|l|}{ DM Onset } & \multirow[b]{2}{*}{$p$ value } & \multirow[b]{2}{*}{ f-ratio value } \\
\hline & & & Pre $\operatorname{PCd}(n=33)$ & At PCd $(n=10)$ & Post PCd $(n=15)$ & & \\
\hline \multirow[t]{2}{*}{ Sex } & Male & $36(62.1)$ & $19(57.6)$ & $8(80.0)$ & $9(60.0)$ & 0.433 & \\
\hline & Female & $22(37.9)$ & $14(42.4)$ & $2(20.0)$ & $6(40.0)$ & 0.083 & \\
\hline \multirow[t]{4}{*}{ Site of Primary Tumour } & Head & $38(65.5)$ & $22(66.7)$ & $4(40.0)$ & $12(80.0)$ & 0.117 & \\
\hline & Body & $12(20.7)$ & $6(18.2)$ & $4(40.0)$ & $2(13.3)$ & 0.235 & \\
\hline & Tail & $5(8.6)$ & $4(12.1)$ & $1(10.0)$ & $0(0.0)$ & 0.719 & \\
\hline & Unknown & $3(5.2)$ & $1(3.0)$ & $1(10.0)$ & $1(6.7)$ & 0.653 & \\
\hline \multirow[t]{5}{*}{ Stage at PC Diagnosis } & Stage 1 & $3(5.2)$ & $2(6.1)$ & $1(10.0)$ & $0(0.0)$ & 0.766 & \\
\hline & Stage 2 & $15(25.9)$ & $8(24.2)$ & $0(0.0)$ & $7(46.7)$ & 0.115 & \\
\hline & Stage 3 & $13(22.4)$ & $7(21.2)$ & $1(10.0)$ & $5(33.3)$ & 0.379 & \\
\hline & Stage 4 & $26(44.8)$ & $15(45.5)$ & $8(80.0)$ & $3(20.0)$ & 0.013 & \\
\hline & Unknown & $1(1.7)$ & $1(3.0)$ & $0(0.0)$ & $0(0.0)$ & 0.340 & \\
\hline \multirow[t]{2}{*}{ Surgery } & Yes & $11(19.0)$ & $4(12.1)$ & $2(20.0)$ & $5(33.3)$ & 0.221 & \\
\hline & No & $47(81.0)$ & $29(87.9)$ & $8(80.0)$ & $10(66.7)$ & & \\
\hline \multirow[t]{2}{*}{ Chemotherapy } & Yes & $42(72.4)$ & $20(60.6)$ & $8(80.0)$ & $14(93.3)$ & 0.053 & \\
\hline & No & $16(27.6)$ & $13(39.4)$ & $2(20.0)$ & $1(6.7)$ & & \\
\hline \multirow[t]{2}{*}{ Radiotherapy } & Yes & $14(24.1)$ & $10(30.3)$ & $1(10.0)$ & $3(20.0)$ & 0.384 & \\
\hline & No & $44(75.9)$ & $23(69.7)$ & $9(90.0)$ & $12(80.0)$ & & \\
\hline Mean Age (years) & & 68.5 & 67.8 & 67.1 & 70.9 & 0.515 & 0.671 \\
\hline
\end{tabular}


Fig. 1 Kaplan meier plot of overall survival (months) for DM status

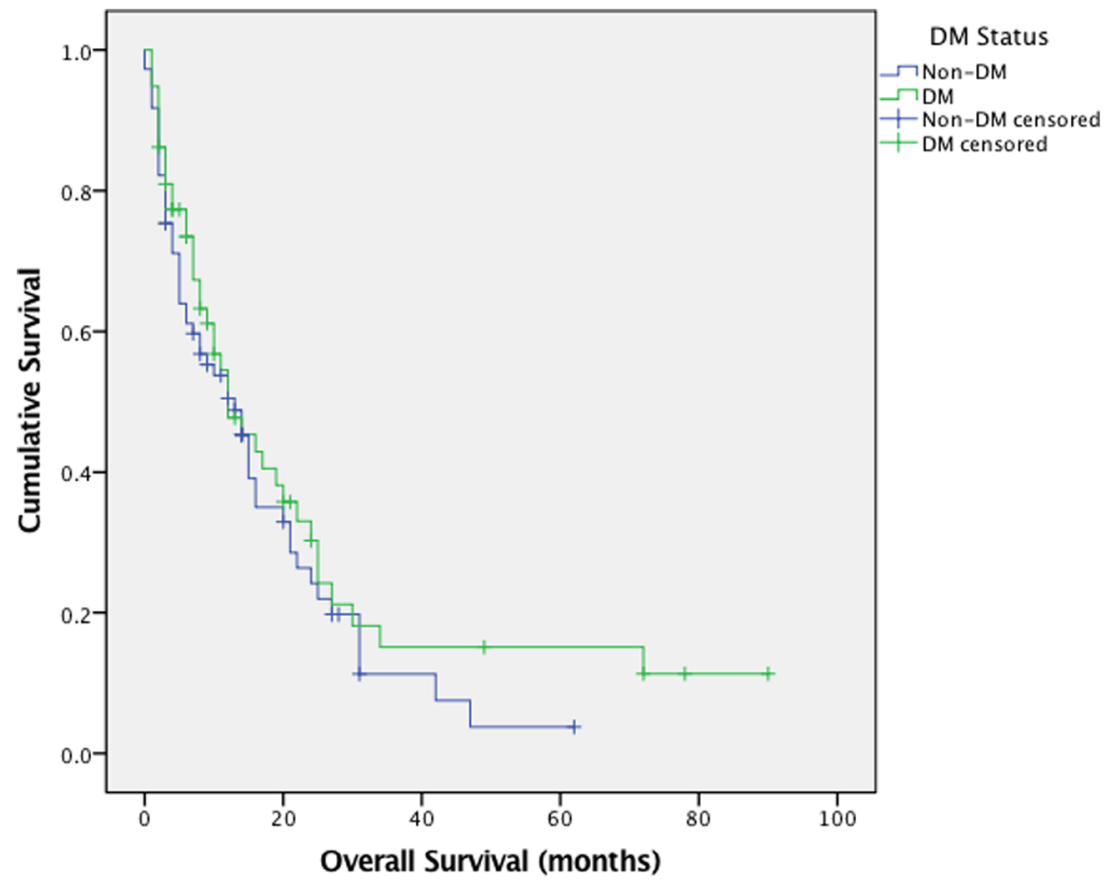

the duration and onset of DM on overall survival. For example, a number of retrospective cohort studies had only found an association between lower OS in patients with 'long-term pre-existing' diabetes $[6,8]$.
There are also many studies that have found an association between DM status and an increased OS [9, 10]. However, further investigations have attempted to start evaluating the role of anti-diabetics on such outcome.

Table 3 Clinical variables mean and median survival (months) with 95\% confidence intervals

\begin{tabular}{|c|c|c|c|c|c|}
\hline Variables & & $\begin{array}{l}\text { Mean Survival } \\
\text { (months) }\end{array}$ & $\begin{array}{l}95 \% \text { Confidence } \\
\text { Intervals }\end{array}$ & $\begin{array}{l}\text { Median Survival } \\
\text { (months) }\end{array}$ & $\begin{array}{l}95 \% \text { Confidence } \\
\text { Intervals }\end{array}$ \\
\hline All patients & & 20.557 & $15.544-25.570$ & 12.0 & $8.543-15.457$ \\
\hline \multirow[t]{2}{*}{ Diabetes Status } & $\mathrm{DM}$ & 23.733 & $15.229-32.237$ & 12.0 & $5.936-18.064$ \\
\hline & Non DM & 16.254 & $12.183-20.324$ & 13.0 & $8.610-17.390$ \\
\hline \multirow[t]{2}{*}{ Sex } & Male & 20.372 & $14.132-26.612$ & 12.0 & $7.905-16.095$ \\
\hline & Female & 20.053 & $12.634-27.472$ & 12.0 & $6.405-17.595$ \\
\hline \multirow[t]{4}{*}{ Site of Primary Tumour } & Head & 24.703 & $17.759-31.647$ & 16.0 & $13.037-18.963$ \\
\hline & Body & 8.318 & $5.330-11.305$ & 6.0 & $2.934-9.066$ \\
\hline & Tail & 5.667 & $1.650-9.683$ & 2.0 & $0.326-3.674$ \\
\hline & Unknown & 22.557 & $13.691-31.784$ & 19.0 & $13.431-24.569$ \\
\hline \multirow[t]{5}{*}{ Stage at PC Diagnosis } & Stage 1 & 14.400 & $7.245-21.555$ & 12.0 & $1.265-22.735$ \\
\hline & Stage 2 & 17.379 & $12.374-22.384$ & 15.0 & $9.113-20.887$ \\
\hline & Stage 3 & 43.390 & $28.916-57.864$ & 31.0 & $20.067-41.933$ \\
\hline & Stage 4 & 10.717 & $6.395-15.039$ & 5.0 & $2.292-7.708$ \\
\hline & Unknown & 10.000 & $4.697-15.303$ & 14.0 & $0.000-28.038$ \\
\hline \multirow[t]{2}{*}{ Surgery } & Yes & 29.136 & $16.870-41.402$ & 16.0 & $10.650-21.350$ \\
\hline & No & 16.892 & $12.348-31.437$ & 11.0 & $6.804-15.196$ \\
\hline \multirow[t]{2}{*}{ Chemotherapy } & Yes & 25.725 & $19.144-32.305$ & 17.0 & $11.539-22.461$ \\
\hline & No & 7.426 & $5.116-9.735$ & 4.0 & $2.093-5.907$ \\
\hline \multirow[t]{2}{*}{ Radiotherapy } & Yes & 16.515 & $11.775-21.254$ & 16.0 & $8.345-23.655$ \\
\hline & No & 22.294 & $15.756-28.833$ & 12.0 & $8.333-15.667$ \\
\hline
\end{tabular}


Table 4 Univariate and multivariate analysis using cox regression model: Hazard ratio (HR), 95\% confidence intervals (95\% CI)

\begin{tabular}{|c|c|c|c|c|c|c|c|}
\hline \multirow[t]{2}{*}{ Variables } & & \multicolumn{3}{|c|}{ Univariate analysis } & \multicolumn{3}{|c|}{ Multivariate analysis } \\
\hline & & HR & $95 \% \mathrm{CI}$ & $p$ value & HR & $95 \% \mathrm{CI}$ & $p$ value \\
\hline \multirow[t]{2}{*}{ DM Status } & DM & 0.817 & $0.541-1.234$ & 0.336 & & & \\
\hline & Non-DM & 1 & & & & & \\
\hline \multirow[t]{2}{*}{ Sex } & Male & 1.013 & $0.671-1.530$ & 0.95 & & & \\
\hline & Female & 1 & & & & & \\
\hline \multirow[t]{4}{*}{ Site of Primary Tumour } & Head & 0.549 & $0.363-0.830$ & 0.004 & 1.470 & $0.658-3.286$ & 0.348 \\
\hline & Body & 2.397 & $1.450-3.962$ & 0.001 & 2.486 & $1.007-6.140$ & 0.048 \\
\hline & Tail & 3.212 & $1.692-6.098$ & 0.000 & 4.213 & $1.440-12.330$ & 0.009 \\
\hline & Unknown & 0.602 & $0.302-1.198$ & 0.148 & & & \\
\hline \multirow[t]{5}{*}{ Stage at PC Diagnosis } & Stage 1 & 0.794 & $0.250-2.518$ & 0.695 & & & \\
\hline & Stage 2 & 0.946 & $0.586-1.528$ & 0.82 & & & \\
\hline & Stage 3 & 0.239 & $0.133-0.428$ & 0.000 & 0.281 & $0.074-1.058$ & 0.061 \\
\hline & Stage 4 & 3.153 & $2.082-4.773$ & 0.000 & 1.163 & $0.348-3.886$ & 0.807 \\
\hline & Unknown & 1.230 & $0.386-3.921$ & 0.727 & & & \\
\hline \multirow[t]{3}{*}{ PC Treatments } & Surgery & 0.601 & $0.373-0.971$ & 0.038 & 1.278 & $0.670-2.438$ & 0.456 \\
\hline & Chemotherapy & 0.298 & $0.189-0.471$ & 0.000 & 0.484 & $0.273-0.858$ & 0.013 \\
\hline & Radiotherapy & 1.022 & $0.646-1.618$ & 0.925 & & & \\
\hline \multirow[t]{3}{*}{ DM Onset } & Pre PCd & 1.030 & $0.647-1.641$ & 0.901 & & & \\
\hline & At PCd & 1.454 & $0.668-3.163$ & 0.345 & & & \\
\hline & Post PCd & 0.501 & $0.251-1.002$ & 0.051 & & & \\
\hline
\end{tabular}

A number of studies have suggested that metformin holds significant prognostic implications in PC patients [10]. These findings are supported by research in to the possible role of metformin in anti-neoplastic biochemical signalling mechanisms [11, 12]. However, it is important to note that such interactions are not seen with other anti-diabetic agents such as sulfonylureas and exogenous insulin therapy [13].

In contrast, there is also evidence suggesting that DM status is associated with a poorer prognosis and decreased OS [8, 14, 15]. It is believed that DM exerts its effect through engaging with the intracellular metabolism of cancer cells, favouring a proliferative state [16]. However, there is still much disagreement between the impact of certain DM sub-types and the role of confounding variables. Some studies have shown that OS for PC is worse in patients with new-onset diabetes [4]. Suggestions have been that the pathophysiology varies between different onset groups of DM patients. This is since new-onset DM in PC patients is now thought to be of paraneoplastic origin [17]. The precise pathophysiology is still inconclusive but a number of different proposals regarding cancer induced peripheral insulin resistance and cancer mediated B cell destruction have been made [18], alongside the identification of potential diabetogenic agents such as adrenomedullin [17].
There were a number of limiting factors associated with this particular study. Most significantly, the sample size was small in comparison to other studies in this area of interest. Furthermore, the confounding variables considered were limited to the data that was only consistently available from all patients' notes. The study did not consider some key exposure variables outline by other literature in this discussion e.g. Antidiabetic use, co-morbidities, BMI etc. The study also lacks in detail when investigating the cancer treatments received by patients. The diagnosis of DM in this study shares inconsistency with other studies and no consideration was taken about the role of diabetes management (extent of blood glucose control) on survival outcomes. However, time dependent variables are difficult to apply to a cox proportional hazard model.

\section{Conclusion}

In conclusion, the study indicates that there is no significant relationship between DM status in pancreatic cancer with overall survival. Such findings join a list of existing, conflicting literature. It is important to note that this study has not ruled out a relationship between DM status and survival but instead highlighted the need for future studies to form a more detailed methodology that considers a more extensive multivariable analysis. 
Acknowledgements University of Cardiff Medical School, Velindre Cancer Centre.

\section{Compliance with ethical standards}

Conflict of interest Harry Kellam: No conflict of interest to declare. Kein-Leong Yim: No conflict of interest to declare.

Ethical approval All procedures performed in studies involving human participants were in accordance with the ethical standards of the South Wales Ethics committee.

Informed consent As this retrospective study was observational and link anonymised, no patient informed consent was required.

\section{References}

1. Welsh Cancer Intelligence and Surveillance Unit | Cancer Mortality in Wales. Wcisu.wales.nhs.uk. 2018. [Accessed 24 Apr 2018] Available from: http://www.wcisu.wales.nhs. uk/cancer-mortality-in-wales

2. Welsh Cancer Intelligence and Surveillance Unit | Cancer Survival in Wales. Wcisu.wales.nhs.uk. 2018. [Accessed 24 Apr 2018] Available from: http://www.wcisu.wales.nhs.uk/ cancer-survival-in-wales-1

3. Welsh Cancer Intelligence and Surveillance Unit | Cancer incidence by stage at diagnosis in Wales. Wcisu.wales.nhs.uk. 2018. [Accessed 24 Apr 2018] Available from: http://www.wcisu.wales. nhs.uk/cancer-incidence-by-stage-at-diagnosis-i-1

4. Hart P, Chari S. Diabetes mellitus and pancreatic Cancer. Pancreas. 2013;42(8):1207-9.

5. Dandona M, Linehan D, Hawkins W, Strasberg S, Gao F, WangGillam A. Influence of obesity and other risk factors on survival outcomes in patients undergoing Pancreaticoduodenectomy for pancreatic Cancer. Pancreas. 2011;40(6):931-7.

6. Hwang A, Narayan V, Yang Y. Type 2 diabetes mellitus and survival in pancreatic adenocarcinoma. Cancer. 2012;119(2):404-10.
7. McWilliams R, Matsumoto M, Burch P, Kim G, Halfdanarson T, de Andrade M, et al. Obesity adversely affects survival in pancreatic cancer patients. Cancer. 2010;116(21):5054-62.

8. Mao Y, Tao M, Jia X, Xu H, Chen K, Tang H, et al. Effect of Diabetes Mellitus on Survival in Patients with Pancreatic Cancer: A Systematic Review and Meta-analysis. Sci Rep. 2015;5(1).

9. Beg M, Dwivedi A, Ahmad S, Ali S, Olowokure O. Impact of diabetes mellitus on the outcome of pancreatic Cancer. PLoS One. 2014;9(5):e98511.

10. Choi Y, Kim T, Oh D, Lee K, Han S, Im S, et al. The impact of diabetes mellitus and metformin treatment on survival of patients with advanced pancreatic Cancer undergoing chemotherapy. Cancer Res Treat. 2016;48(1):171-9.

11. Sadeghi N, Abbruzzese J, Yeung S, Hassan M, Li D. Metformin use is associated with better survival of diabetic patients with pancreatic Cancer. Clin Cancer Res. 2012;18(10):2905-12.

12. Radulovic S, Nagy A, Szoke B, Schally A. Cytotoxic analog of somatostatin containing methotrexate inhibits growth of MIA $\mathrm{PaCa}-2$ human pancreatic cancer xenografts in nude mice. Cancer Lett. 1992;62(3):263-71.

13. Bowker S, Majumdar S, Veugelers P, Johnson J. Increased Cancerrelated mortality for patients with type 2 diabetes who use sulfonylureas or insulin: response to Farooki and Schneider. Diabetes Care. 2006;29(8):1990-1.

14. Toriola A, Stolzenberg-Solomon R, Dalidowitz L, Linehan D, Colditz G. Diabetes and pancreatic cancer survival: a prospective cohort-based study. Br J Cancer. 2014;111(1):181-5.

15. Wang J, Shen H, Zhan M, Wang W, Yang D. Impact of diabetes mellitus on the survival of pancreatic cancer: a meta-analysis. OncoTargets Ther. 2016;9:1679-88. https://doi.org/10.2147/OTT. S95744.eCollection2016

16. Fisher W, Boros L, Schirmer W. Insulin promotes pancreatic Cancer: evidence for endocrine influence on exocrine pancreatic tumors. J Surg Res. 1996;63(1):310-3.

17. Aggarwal G, Ramachandran V, Javeed N, Arumugam T, Dutta S, Klee G, et al. Adrenomedullin is up-regulated in patients with pancreatic Cancer and causes insulin resistance in $\beta$ cells and mice. Gastroenterology. 2012;143(6):1510-1517e1.

18. Bao Y, Giovannucci E, Kraft P, Stampfer M, Ogino S, Ma J, et al. A prospective study of plasma adiponectin and pancreatic Cancer risk in five US cohorts. JNCI: J Natl Cancer Inst. 2012;105(2):95-103. 